\title{
Research on the Dilemma and Development Path of Entrepreneurial University Construction in China
}

\author{
Puhua $\mathrm{Li}^{1, *}$ \\ ${ }^{1}$ The General Office, Jiangsu University, Zhenjiang, Jiangsu 212013, China \\ *Corresponding author. Email: lipuhua@126.com
}

\begin{abstract}
As a new goal in the transformation and development of colleges and universities, entrepreneurial universities are equipped with powerful control core, broadened development periphery, diversified funding, active academic heartland, and integrated entrepreneurial culture. Influenced by many factors, such as higher education management system, industrial integration development and innovative organization construction, the construction of entrepreneurial universities in China is proceeding slowly. In the new period, the development plan of entrepreneurial universities should be coordinated, the benefits of scientific research achievements transformation should be improved, the internationalization of higher education should be promoted, and the construction of entrepreneurial universities should be continuously strengthened.
\end{abstract}

Keywords: Entrepreneurship, Entrepreneurial university, Innovative university.

\section{INTRODUCTION}

At present, China has entered the stage of highquality development in the "14th Five-Year Plan": the integration of education, industry and society is getting higher and higher, and the development of science and technology and industry increasingly needs the support of innovative achievements in higher education, which also puts forward higher requirements for the conjunctive development of higher education. As a new model of the transformation and development of colleges and universities, entrepreneurial universities are of great significance to accurately grasp the new development stage, thoroughly implement the new development concept and accelerate the construction of a new development pattern.

\section{CONNOTATION AND MAIN CHARACTERISTICS OF ENTREPRENEURIAL UNIVERSITIES}

According to American scholar Ezkowitz, "from a historical point of view, entrepreneurial universities are institutions of preserving and spreading knowledge that continue the Middle Ages and then develop into multi-functional institutions that create new knowledge and put it into practical application." [1] Burton Clark says: "Entrepreneurial universities are places that are actively seeking to escape the rigors of government regulation and departmental standards. They look for specific organizational entities; and they actively try to be different, even if it's a risk. They look for opportunities in the market. There is a firm belief that rather than risk merely maintaining the traditional forms and practices of the university, it is better to risk some tentative changes in the character of the university." [2] It is not difficult to see that the orientation and functions of entrepreneurial universities are significantly different from those of traditional teaching and research universities. Burton Clark combined the cases of five universities, including the University of Warwick, the University of Twent, the University of Strathclyde, the University of Sweden and the University of Finland, and put forward five paths for the transformation to entrepreneurial universities, which are also considered to be the unique organizational characteristics of entrepreneurial universities: powerful control core, broadened development periphery, diversified funding, active academic heartland, and integrated entrepreneurial culture. [3] As a more open and integrated way of school development, entrepreneurial universities pay more attention to the creative cultivation of students and 
strengthen the transformation and application of scientific and technological achievements, which has important reference significance for solving the bottleneck problem of China's industrial development and promoting the reform of the internal governance system of colleges and universities.

\section{DIFFICULTIES IN THE CONSTRUCTION OF ENTREPRENEURIAL UNIVERSITIES IN CHINA}

Benefiting from the concept of marketization, academicalization, socialization and entrepreneurship, entrepreneurial universities effectively combine production, learning and research on the basis of research universities, thus enhancing their competitiveness and improving the level of school running. As a new model of university development, it has exerted a lot of influence on the development of universities themselves. [4] However, due to the differences in school-running systems and mechanisms, many problems are encountered in the process of transforming entrepreneurial universities, mainly manifested in the following aspects:

\subsection{The Administrative System of Higher Education}

There is a paradox in the policy environment of higher education in China: on the one hand, the government actively promotes the reform of "deadministration" to expand the autonomy of universities in running schools, but on the other hand, the government's various efforts further strengthen the dependency of universities, showing a phenomenon of "opposite effect" in coordinating the relationship between the government and universities. [5] Entrepreneurial university is a new type of university with flexibility and autonomy in running school. It has established a good cooperative relationship with the government. As for the management of entrepreneurial universities in this kind of loose cooperative relationship, the government focuses on the regular allocation of funds to universities and the evaluation and supervision of teaching quality and research level. At the same time, the university has established a close cooperative relationship with the industry (market), which can not only increase the funding source of the university, but also help to strengthen cooperation and exchanges, promote the overall level of the university, and form a mutually beneficial and win-win mechanism. In recent years, China has reformed the higher education management system, and implemented the three-level management of state, local and school. However, due to the influence of educational expenses and personnel system, especially the institution setting, personnel system and administrative management of faculty and staff, there are obstacles to the construction of entrepreneurial universities in China.

\subsection{Integration of Industries}

The privatization and profit-making mode of American higher education greatly activates the autonomy and times of running a school. The marketoriented mode of running a school promotes the timely updating of educational content and makes its teaching organization and methods more flexible. The UK, on the other hand, has established a corporate culture in its higher education system, where business leaders have organized industry and higher education committees to encourage cooperation between industry and higher education, advocate greater access to higher education and more diversified higher education, as well as the transformation of knowledge outcomes to science and technology supply. [6] By actively participating in market activities, entrepreneurial universities seek research funds and research problems from market cooperation, accelerate the transformation of scientific research results to achieve economic benefits, integrate teaching into scientific research projects, improve students' practical ability and innovation and entrepreneurship level, and promote the synergistic improvement of regional development and school-running level. Although China has issued relevant system documents to vigorously promote the integration of science and education and industry and education, the scientific research achievements of colleges and universities are often reflected in scientific papers, patent achievements, academic awards, etc., the transformation and application of achievements is still not high, the problem of talent training being separated from the market is serious, and the cultural environment for the establishment of entrepreneurial universities is not sufficient.

\subsection{The Construction of Innovative Organization}

As economic entrepreneurs, they can be not only companies, individuals, but also university organizations or government agencies, but they generate income in different forms. It can be said that entrepreneurship takes place in the cooperation and communication between individuals and organizations within a wide range of institutions. The 
innovative organizational forms of entrepreneurial universities are mainly manifested in the three aspects of interdisciplinary research organization, university technology transfer organization and peripheral development organization such as science park, and they need to establish a wide range of connections with the outside society. In the United States, universities have set up technology transfer offices to make industry more accessible to various sources of intellectual property. In the reform of recent years, some universities in China have also set up corresponding innovation organizations such as science and technology transfer departments and technology transfer centers. However, the transformation and development of entrepreneurial universities in China are hindered organizationally due to many reasons, such as the low level of interdisciplinary research, the imperfect transfer mechanism of university scientific and technological achievements, and the incomplete trans-boundary organization of university science and technology parks.

\section{THE DEVELOPMENT PATH OF ENTREPRENEURIAL UNIVERSITY CONSTRUCTION IN CHINA}

The university is the product of its own and the environment. Its unique spirit and behavior make the university maintain the relative stability of the system and the continuity of identity, but the change of the environment and its internal and external pressure will inevitably prompt the university to carry out the adaptive reform. With the continuous expansion of the scale of higher education and the huge investment of funds, universities in the knowledge economy environment take the initiative to integrate into the development of industrial economy, and realize their functions of serving the society and promoting economic development in various forms. The practical path of sinicization of entrepreneurial universities can only be achieved from the perspective of individual colleges and universities. Individual colleges and universities take the lead in realizing the transformation, the premise is the change of ideology. [7] As an important way of development in the new stage, the ecological support for entrepreneurial universities can be constructed from the following aspects.

\subsection{The Development Plan of Entrepreneurial Universities Should be Comprehensively Integrated}

The development of any university is not blind, and any organization has a life cycle. Therefore, universities should not only define their own position, but also make long-term strategic planning. The orientation of a university refers to how a university determines its own status and development direction in the process of running a school, including the level, type and scale of a university, which is the development direction and goal of a university as well as the future direction of a university. It needs shrewd managers and practitioners, and it is extremely urgent to strengthen the research of university culture construction and university strategic development. In particular, China's higher education has entered the stage of popularization, and the phenomenon of inaccurate positioning and blind pursuit of promotion in colleges and universities is widespread, which makes the dominant disciplines in universities fail to develop effectively. "Knowledge industrialization" is the core mission of entrepreneurial universities, which can make universities more closely connected with knowledge users. In addition, universities are seen as economic actors with their own property rights, which become their prominent organizational feature. However, schools that want to become entrepreneurial universities should not blindly pursue the external organizational scale, but should strengthen the entrepreneurial culture within the organization, especially the connection between scientific research achievements and transformation, so as to improve the level of running a university. It can be said that overall development strategic planning is the foundation of establishing entrepreneurial universities.

\subsection{The Efficiency of Commercialization of Scientific Research Results Should be Comprehensively Improved}

Entrepreneurial universities construct the relationship model of university-governmentindustry, in which universities are the producers and inheritors of knowledge, the accelerators of knowledge application and the promoters of local economic and social development. Their research projects come from the basic research of the government, the market and their own academic development. The results of research will also be used in government, the market and its own academic institutions, instead of only in academic institutions. 
In the era of rapid development of high-tech, knowledge economy has undoubtedly become the main economic form. Many companies need to base themselves on advanced concepts and professional knowledge. Industrial development needs not only the support from the government, but also advanced technologies and excellent graduates provided by universities. In the cooperation and exchange between universities, market industry and government, the research of universities and government projects are on the same direction, the cooperation bridge between universities and market industry is established, and the direct transformation of scientific research achievements of universities is realized. In the early stage, MIT used intermediary organizations such as academic committees and research companies that peer-review inventions to carry out the transformation of scientific research results, which brought great inconvenience to the transformation of academic results and seriously affected the efficiency and benefit of the transformation of scientific research results. However, with the reform and development of MIT, the Technology Transfer Office was established to directly carry out the transformation of scientific research results, which enhanced the enthusiasm of professors for scientific research and also brought good reputation and benefits to the university. Therefore, the construction of the organizational system for the transformation of scientific and technological achievements should be strengthened, and the transformation of scientific and technological achievements has become the top priority for the establishment of entrepreneurial universities.

\subsection{Internationalization of Higher Education Should Be Promoted in an All-round Way}

The competition in economics, politics, science and technology is ultimately a competition for talents, but more importantly, a competition for education. Internationalization of higher education has become a universal trend in the world. Promoting internationalization of higher education in China can enable Chinese colleges and universities to introduce high-quality educational resources from abroad, increase the channels of educational investment, and promote the educational output of Chinese colleges and universities to strengthen international educational exchanges, learning and cooperation. In recent years, China's education has gradually become more open. Thanks to the exchange of students and teachers and the granting of degree-conferring rights with foreign universities, cooperative educational centers are be set up abroad, attracting foreign students by virtue of traditional majors and disciplines. However, the level and depth of international exchanges and cooperation need to be improved. In particular, the cooperation and exchanges with international organizations and their role in the international governance system are still insufficient. The openness of entrepreneurial universities is not only within the region, but also within the international scope. Its students and teachers come from many countries, as well as its research strength and market. Moreover, entrepreneurial universities have carried out extensive cooperation with international organizations. Therefore, comprehensive strategic partnership should be established with universities around the world to promote the two-way exchange of international talent training. Cooperation on global community governance and international cooperation on frontier research should be strengthened, and efforts should be made to build an international and domestic dual-cycle system of higher education.

\section{CONCLUSION}

Entrepreneurial universities that pay more attention to the transformation of scientific research achievements adhere to teaching for development, research-based learning, and the combination of teaching and research. Entrepreneurial university, as a synthesis of educational modes and ideas, is not suitable for all universities. The new pattern and characteristics of higher education in the postepidemic era put forward new requirements for the convolutional development of schools. As a new type of university, entrepreneurial university needs scientific and reasonable development planning, internal governance system reform and innovative entrepreneurial culture. In this way, the innovative achievements of the school can be effectively transformed into the industry and social life, making the school a strategic support force for social development.

\section{AUTHORS'CONTRIBUTIONS} Li.

This paper is independently completed by Puhua

\section{REFERENCES}

[1] Henry Ezkowitz. MIT and rise of entrepreneurial science [M]. translated by Wang Sunyu and Yuan Bentao. Beijing: Tsinghua University Press, 2007: 13. (in Chinese) 
[2] Burton Clark. Establishing an entrepreneurial university: a path to organizational transformation $[\mathrm{M}]$. translated by Wang Chengxu. Beijing: People's Education Press, 2003: 2. (in Chinese)

[3] Li Xiaobo, Li Puhua. Enlightenments of the Entrepreneurial University on Construction of Quality Universities in China [J]. Journal of Higher Education Management, 2011, 5(05): 47-50. (in Chinese)

[4] Cheng Tianjun, Lu Menghan. 'Deadministrating': Policy Support for Implementing and Enlarging the Autonomy of Running Universities [J]. Global Education, 2017, (12): 69-84. (in Chinese)

[5] Sheila Slaughter, Larry Leslie, translated by Liang Xiao, and Li Li. Academic Capitalism: Politics, Policies, and The Entrepreneurial University $[\mathrm{M}]$. Beijing: Peking University Press, 2008: 3. (in Chinese)

[6] Fu Bajun, Wang Jiatong. Chinese Practice of Entrepreneurial University: Its Influencing Factors and Fading Routes [J]. Education Research Monthly, 2020, (11): 3-8. (in Chinese)

[7] Li Puhua, Xue Hongli, etc. Comparison of and Reflections on Entrepreneurial Universities in Europe and America: Taking the Case of MIT and Warwick University [J]. Journal of Higher Education Management, 2014, 8(01): 116-120. (in Chinese) 